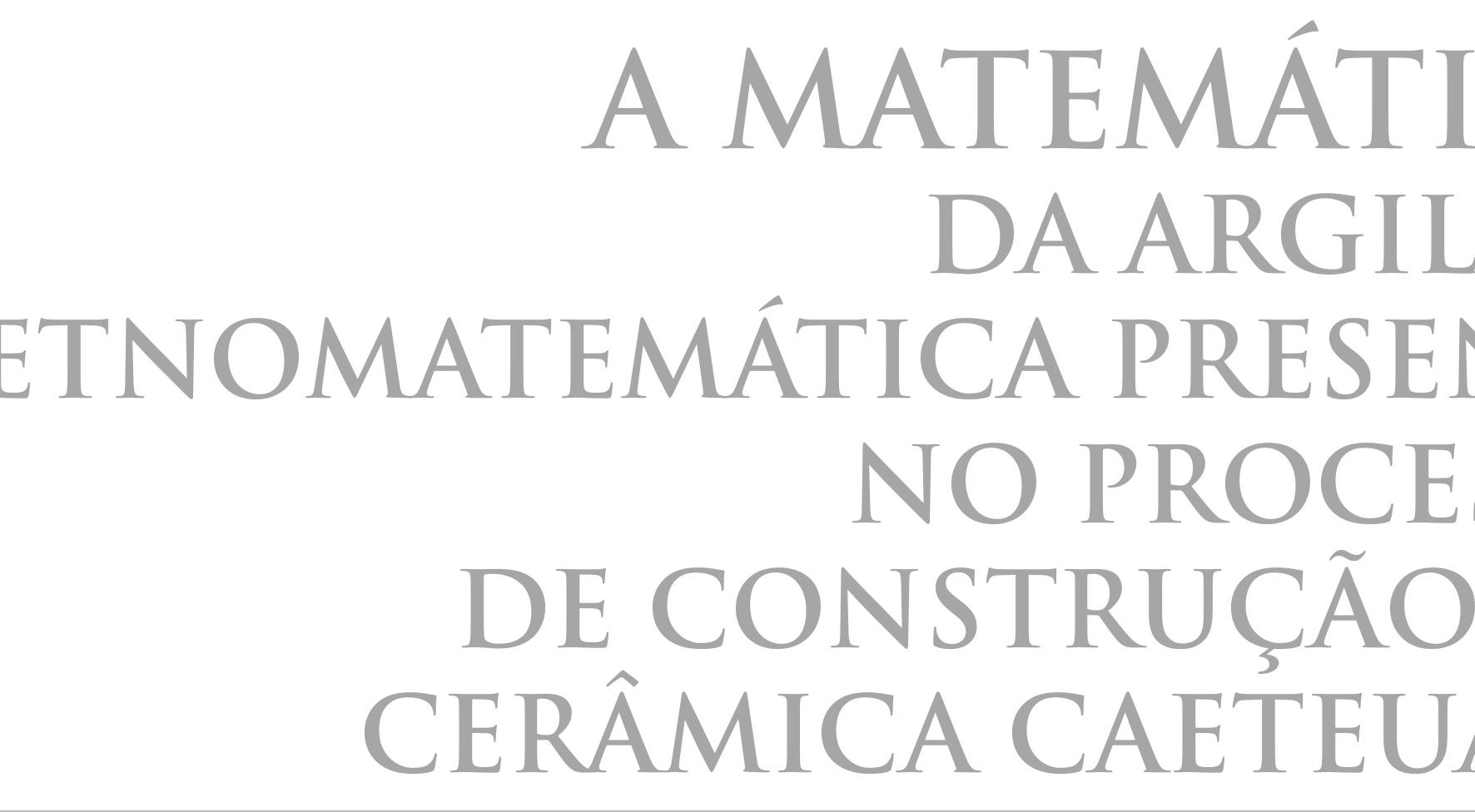




\section{A MATEMÁTICA DA ARGILA: A ETNOMATEMÁTICA PRESENTE NO PROCESSO DE CONSTRUÇÃO DA CERÂMICA CAETEUARA ${ }^{1}$}

\section{SAMUEL ANTONIO SILVA DO ROSARIO²}

MESTRANDO NO PROGRAma de Pós GRAdUAÇÃo EM LiNGUAGENS E SABERES NA AMAZÔNIA (UFPA)

LUIS JUNIOR COSTA SARAIVA3

UNIVERSIDADE FEDERAL DO PARÁ/CAMPUS BRAGANÇA 
A tradição de construir objetos através da argila é encontrada em diversas sociedades e culturas, fazendo parte da história de povos distintos e guardando informações importantes sobre o contexto no qual esse saber foi gerado. Suas variadas formas e cores mostram as diversas aplicações e significados para cada grupo social que se utiliza dessa prática, nesse sentido o processo de construção de peças de cerâmica envolve muitos saberes, que são gerados através do saber/fazer e transmitidos por meio da observação e da oralidade nas comunidades que detém esse conhecimento milenar.

Conhecer os saberes Etnomatemáticos envolvidos no contexto da cerâmica caeteuara e como esse saber está diretamente ligado à memória, cultura, economia, ecologia, mitos, lendas e à história local, surgiu durante o II Seminário de Questões Socioambientais e Etnobiodiversidade na Amazônia ${ }^{4}$, onde foram propostos vários debates sobre os saberes e práticas tradicionais em um contexto amazônico, intermediados por mestres dos saberes tradicionais da localidade chamada Vila Cuéra, levando em conta a importância dessa localidade para a história regional.

O trabalho foi estruturado durante o evento e, posteriormente, fazendo parte de uma pesquisa de mestrado desenvolvida através do PPGLSA (Programa de Pós-graduação em Linguagens e Saberes na Amazônia) tendo como uma das temáticas a Etnomatemática. As descrições e teorizações surgiram a partir de observações, interpretações e entrevistas realizadas em campo com os moradores locais, que produzem peças a partir da argila. Segundo Gerdes (1991), através da análise das formas geométricas desses objetos, pode-se comprovar que os criadores dessas peças pensam matematicamente, construindo um saber matemático.

Durante o evento, aconteceu uma oficina com o senhor chamado Josias (32 anos), que argumentou que o conhecimento sobre a cerâmica foi herdado de sua mãe e que hoje passa essa prática tradicional para suas filhas. $\mathrm{O}$ ceramista, além de fabricar vasos e panelas de argila, cria também peças mais elaboradas com técnicas aprimoradas, seguindo uma geometria própria onde círculos, quadrados e retângulos predominam correlacionados com as noções de área e volume, pois Josias argumenta que são melhores de construir, seguindo um processo onde o saber/ fazer é organizado empiricamente, gerando as peças primeiro no cognitivo e, posteriormente, concretizadas na argila, nos permitindo conhecer outra dimensão do processo de criação dessas peças em conjunto com materiais como o caripé e taicica $^{6}$ que também são retirados da própria natureza de maneira sustentável. Essa (re) apropriação de sua prática cultural, agregando nesse processo novos elementos é definida segundo Knijnik e Wanderer (2004, p. 146), como um processo de "hibridização cultural". Essa constante redescoberta de valores e características é fruto de um conjunto de práticas de significação que estão permanentemente se reatualizando e se refazendo.

Seguindo as concepções Etnomatemáticas de D’Ambrosio (2005) e Ger- 
des (2007) conseguimos estabelecer relações e interconexões entre ideias matemáticas e outros elementos constituintes culturais, presentes na vida cotidiana dos agentes sociais estudados, pois o cotidiano está impregnado de modos próprios de pensar, organizar e expressar saberes matemáticos em conjunto com os saberes culturais e ecológicos.

O cotidiano é repleto de situações que necessitam do conhecimento matemático, mesmo que de forma empírica, as relações econômicas, ambientais e sociais estão diretamente ligadas às práticas de existência. Para Kastrup (2007, p.152) o ato de construir conhecimento, de conhecer o mundo "está enraizada na ação, na vida prática”. Implica na mobilização de distintos processos cognitivos como a atenção, a percepção, a memória, a emoção, o raciocínio e a linguagem. Nessa abordagem, observamos na existência de práticas etnomatemáticas, relacionadas às necessidades locais, que foram de certa forma, impostas pela própria natureza e pela cultura da qual o homem faz parte, e com a qual está em constante interação.

\section{NOTA}

As fotografias deste ensaio estão relacionadas à pesquisa de mestrado desenvolvida por Samuel Antonio Silva do Rosário, sob orientação do Prof. Dr. Luis Junior Costa Saraiva e com financiamento CAPES junto ao PPLSA/UFPA. Todas as fotografias são de autoria de Samuel A. S. do Rosário.

${ }^{1}$ Nos estudos histórico-sociológicos da região amazônica brasileira na percepção dos ciclos extrativos da economia, a sociedade CAETEUARA compõe um dos cinco mundos aquáticos (Tapajônico, Marajoara, Tocantino, Guajarino), diferenciados por suas fisiografias principais, fauna, flora, rios e baías(...) (CONTENTE e CONTENTE, 2015).

2 Mestrando pelo Programa de Pós Graduação em Linguagens e Saberes na Amazônia(UFPA). Membro dos grupos de pesquisa LELIM (Laboratório de Estudo Linguagem, Imagem e Memórias) e ETTHOS (Educação, Trabalho, Tecnologia, Humanidades e Organização Social). samuel_mat2009@hotmail.com

${ }^{3}$ Doutor em Antropologia. Professor Adjunto FACED/UFPA, Campus de Bragança. Membro do grupo de Pesquisa ESAC (Estudos Socioambientais Costeiros) e Membro dos grupos de pesquisa LELIM (Laboratório de Estudo Linguagem, Imagem e Memórias). luisjsaraiva@yahoo. com.br.

${ }^{4}$ Evento organizado pela Universidade Federal do Pará(Campus-Bragança), Instituto Federal do Pará(Campus-Bragança) e Comunidade Vila Cuéra.

${ }^{5}$ Espécie de árvore nativa, que ao ser misturado com a argila dar resistência a peça confeccionada.

${ }^{6}$ Uma resina vegetal que tem a capacidade de dar brilho a peça.

\section{REFERÊNCIAS}

D'Ambrosio, U. 2005. Sociedade, cultura, matemática e seu ensino. São Paulo: Educação e Pesquisa.

Gerdes, P. 2007. Etnomatemática: reflexões sobre Matemática e diversidade cultural. Ribeirão: Edição Húmus.

Gerdes, P. 1991. Cultura e o despertar do pensamento geométrico. Moçambique: Instituto 
Superior Pedagógico.

Kastrup, V. 2007. A invenção de si e do mundo: uma introducão do tempo e do coletivo no estudo da cognição. São Paulo: Autêntica.

Knijnik, G.; Wanderer, F. 2004. A arte dos azulejos portugueses na metrópole e na colônia: processos de hibridização cultural e saberes no campo da etnomatemática. In: Congresso Brasileiro de Etnomatemática, Natal, RN: EDUFRN.

Contente, F. Contente, A. 2015. O legado histórico na produção da cerâmica caeteuara. Revista Visagem1( 01):43-48.

Samuel Antonio Silva do Rosario samuel_mat2009@hotmail.com

Luis Junior Costa Saraiva luisjsaraiva@yahoo.com.br 

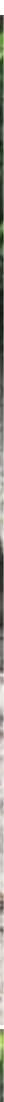

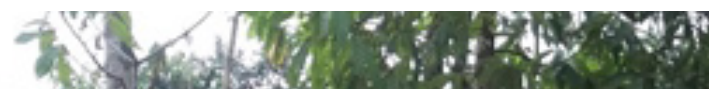


Rosario, S. A. S. do | Saraiva, L. J. C.
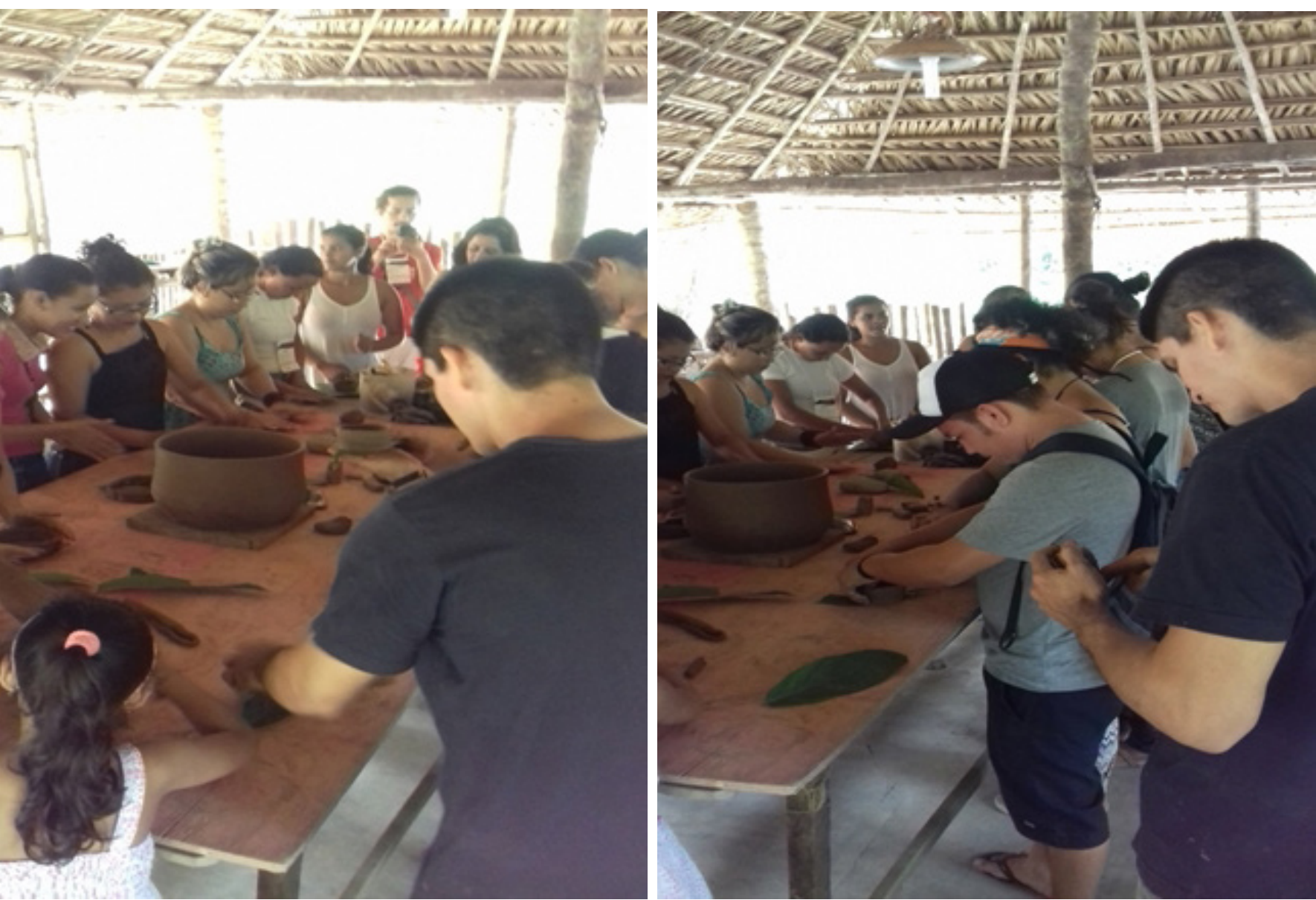

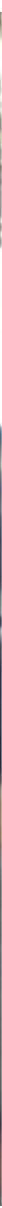
Rosario, S. A. S. do | Saraiva, L. J. C.
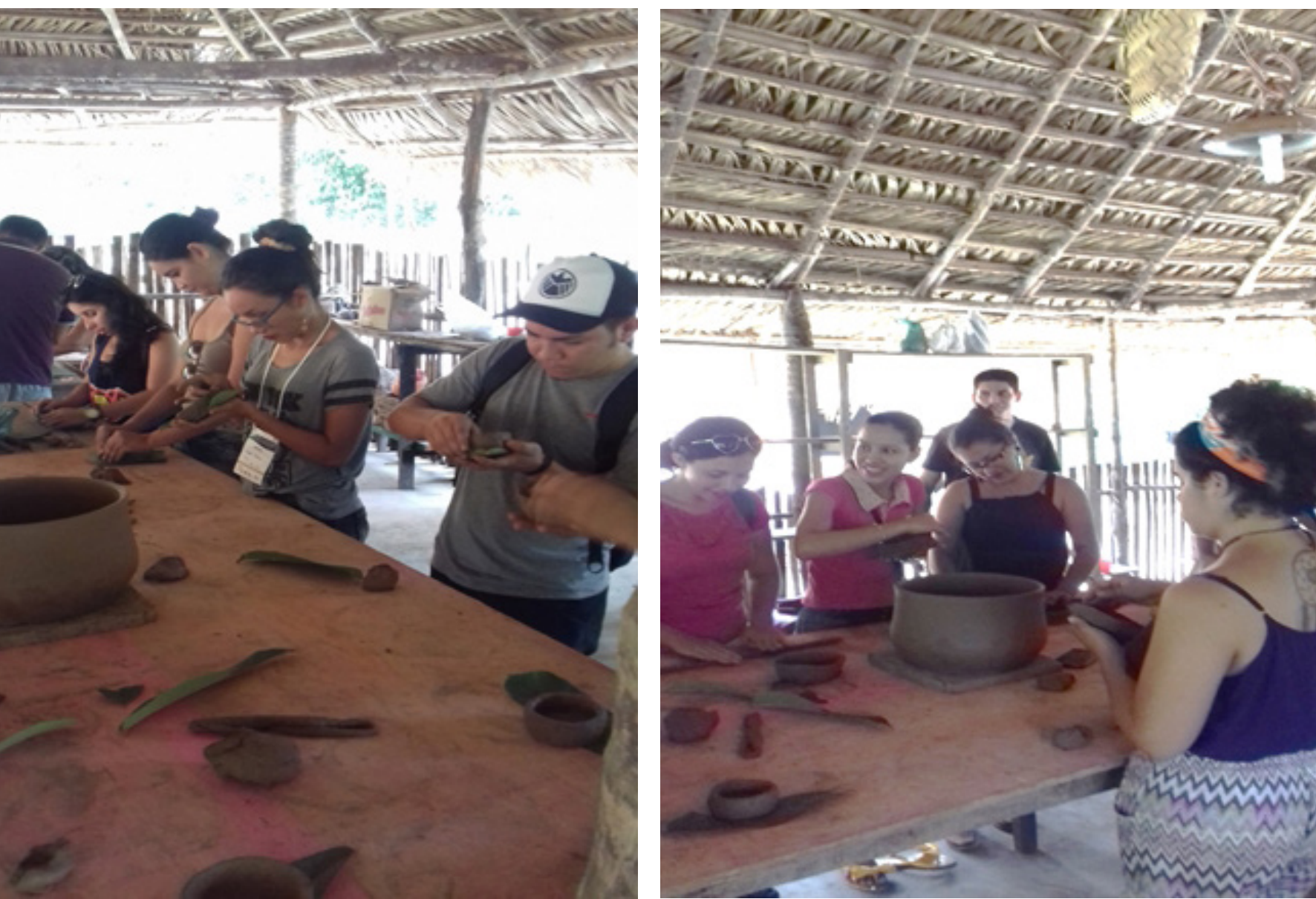


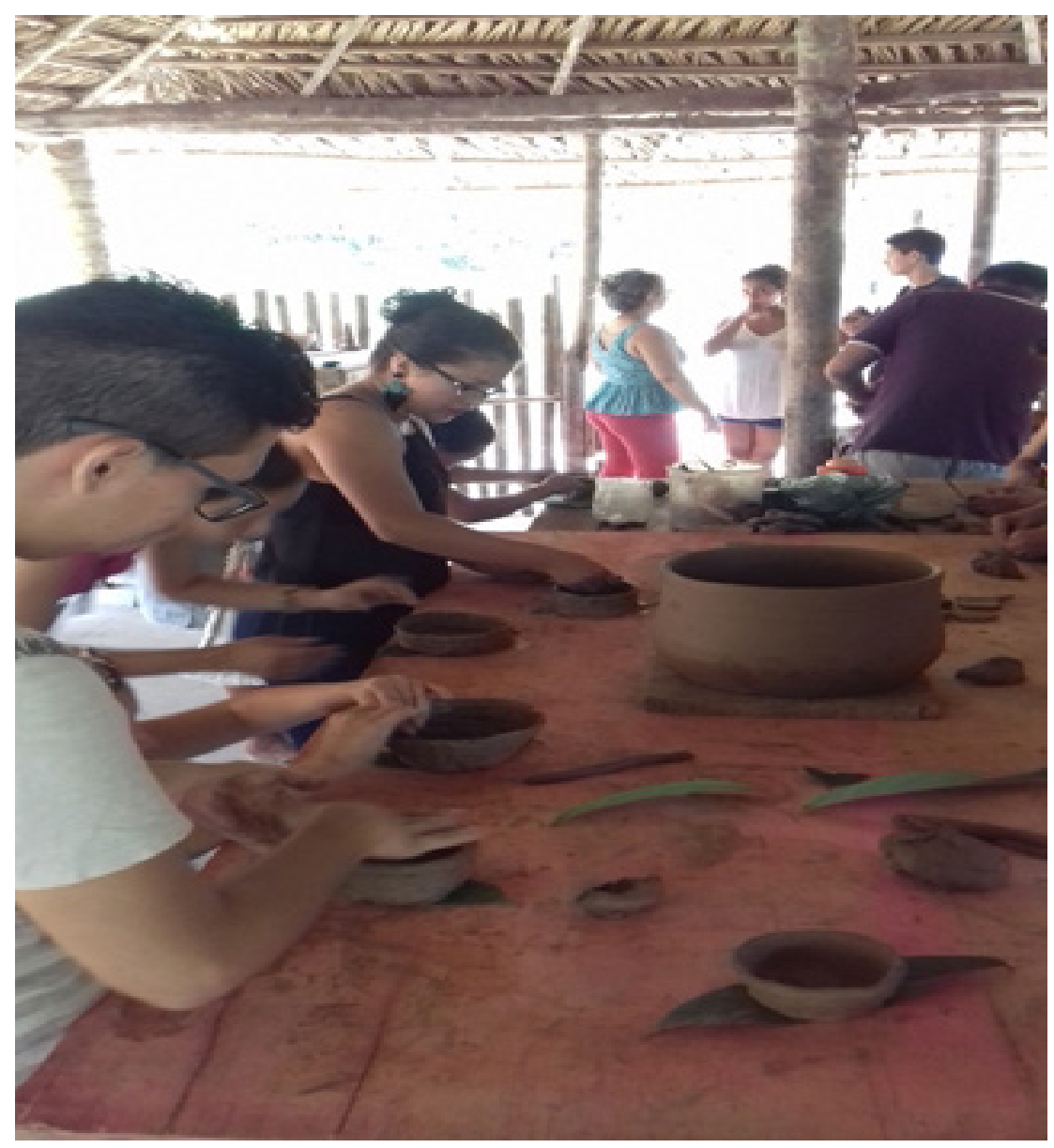

